\section{A matter of taste}

The July/August edition of The Journal of the Canadian Association contains a guest editorial by Dr Wesley J. Dunn, editor of that journal from 1953 to 1958, summarising the changes in dentistry over the five decades since his original appointment. Most of his editorial describes the positive developments for dentistry, but as a final comment he mentions the unprofessional promotional activities by some dentists that he understandably regrets. In particular he highlights the practice of sending your newsletter to the patients of other dentists in an attempt to 'attract' them to your own surgery, an activity I think we would all agree is not in keeping with the expected behaviour of members of a respected profession.

Dr Dunn raises the dilemma of professionalism versus commercialism. We are now encouraged to consider our colleagues as business competitors, an approach that can be difficult for the professional. Examples of the difference in thinking today is that we now have a relaxation of advertising standards for the professions, we are advised to investigate (sometimes covertly) our colleagues' fees, we can get involved in headhunting staff from colleagues and even become involved in the dubious practice of sending a dental nurse round to a 'competitor' pretending to be a potential patient to find out what the practice offers. All of the above are part of a general acceptance today that 'competition' is good, especially for the consumer.

But is that necessarily correct? Dr Dunn was right to put his finger on this subject of competition, because it seems society is determined to follow the path of believing that increased competition is always for the benefit of the consumer. While it may be true in the High Street, is it true for a profession? And, of more relevance to us, is it true of a healthcare profession?

Society, we know, has changed and so have the professions. The days of the paternal doctor or dentist who always 'knew best' and who 'protected' his patients are long gone, and I suspect we are all more comfortable with the modern view of involving patients in their care, discussing options fully and ensuring that patients themselves make treatment decisions based on a thorough understanding of the relevant information. We even have a name for it - informed consent. But while that behaviour seems much more sensible today, is the encouragement of consumerism and competition creating a more unethical and less professional environment for us, or is it the natural evolution of a profession, the way the professions should go to reflect society's needs and expectations?

Perhaps we should consider the words of Dr Dunn in his Canadian editorial to help us find the answer. He comments on the importance of ensuring that any advertising, promotional and business activity is fine as long as it fits into our concept of 'good taste', but then comments on the difficulty of defining 'good taste'. It may sound simplistic, but perhaps that is the answer. Should we always try to move our professional behaviour forward in keeping with the moods and timbre of current thinking, ensuring that everything we do fits into the boundaries of 'good taste'? Thus, to consider the example of advertising, we should be relaxed about increasing advertising and promotional activity in general, but only so long as it remains within our judgement of good taste.

Alas, things can never be so simple. For a start, who decides on the definition of 'good' taste? Are my guidelines the same as yours? If you ask me not to see your patient on a regular basis (perhaps because you referred the patient to me for an expert opinion) does this restrict the rights of the patient to choose their dentist? If I send a mailshot to your patient by chance is that considered to be fair game? Could 'good taste' simply be construed by critics as 'protectionism' again, especially when considering the anti-competitive spirit behind it? When does discussing fees openly (as often happens at BDA meetings) change from professional courtesy to being guilty of attempting some kind of price-fixing cartel?

Sometimes what appears right for society in general (encouraging competion for example) may not only cause difficulty for people in healthcare but be counterproductive for our patients. The real secret is knowing when. 